\title{
Perancangan Ulang Area Terminal Joyoboyo menjadi Area Transit Intermoda Daerah Kota Surabaya
}

\author{
Muhammad Dewawisnu Mahdi dan Murni Rachmawati \\ Jl. Arief Rahman Hakim, Surabaya 60111 \\ E-mail: murnirach@arch.its.ac.id
}

Jurusan Arsitektur Fakultas Teknik Sipil dan Perencanaan Institut Teknologi Sepuluh Nopember

\begin{abstract}
Abstrak-Indonesia termasuk dalam negara yang memilki jumlah penduduk yang banyak yaitu sekitar 240 juta jiwa. Meskipun luas tanah pijak masih cukup luas sekitar 1.9 juta meter persegi namun pemerataan jumlah yang tidak seimbang di beberapa wilayah terutama wilayah perkotaan metropolitan seperti Jakarta dan Surabaya mengakibatkan munculnya berbagai kemacetan yang akhirnya menghambat konsistensi mobilitas terutama saat jam kerja. Rencana pemerintah kota Surabaya untuk mengembangkan serta menambah beberapa jenis moda transportasi baru merupakan sebuah langkah yang harus diambil untuk mengatasi persoalan kepadatan lalu lintas di hampir semua ruas jalan penting di kota Surabaya.

Pemkot Surabaya sudah menyiapkan desain berupa konnsep poin-poin dimana proyek ini akan berlokasi. Penulis membahas sebuah rancangan bangunan stasiun/ Terminal Hub, yang mengutamakan orientasi terhadap kebutuhan publik terutama dalam kemudahan dan efisiensi akses ke sarana dan prasarana transportasi yang berbeda. Penerapan rancangan bangunan ini dilakukan ke arah vertikal guna menghubungkan beberapa sirkulasi penghubung transportasi yang berbeda elevasi ketinggian.
\end{abstract}

Kata Kunci--- (arsitektur, efisiensi, transportasi, hub, terminal, stasiun, lalu lintas)

\section{PENDAHULUAN}

Rencana pemerintah kota Surabaya untuk pengembangan serta penambahan 2 macam jenis moda transportasi baru merupakan sebuah langkah yang harus diambil untuk mengatasi persoalan kepadatan lalu lintas di hampir semua ruas jalan penting di kota Surabaya. Sebagai rencana pemkot Surabaya sudah menyiapkan desain berupa konnsep poin poin dimana proyek ini akan berlokasi. Beberapa lokasi dan dan titik dimana akan dibuat sebuah pengembangan sarana pendukung dua moda transportasi (Monorail dan Trem) [1].

Pemerintah kota Surabaya akan meyebarkan jalur monorail arah Barat-Timur dan trem dari arah UtaraSelatan. Menurut perkiraan pada tahun 2030 kegiatan transportasi akan semakin padat dan jenis moda yang dimilki kota Surabaya saat ini tidak akan mencukupi kebutuhan. Gambar 1, 2, dan 3 menunjukkan beberapa survei aktifitas lalu lintas di kota Surabaya secara umum menurut Pemkot dan Dishub kota Surabaya [2].

Terminal Joyoboyo direncanakan menjadi titik temu anatara kedua moda transportasi baru yaitu Monorel dan Trem. Saat ini area dimaksud sangat sepi meskipun befungsi

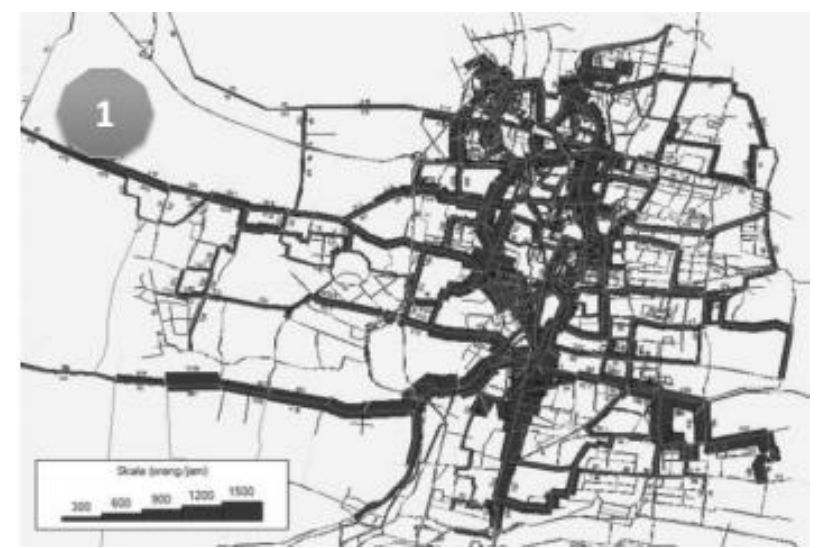

Gambar 1. Analisa Effek Arus lalu lintas (Pemkot Surabaya: 2013)

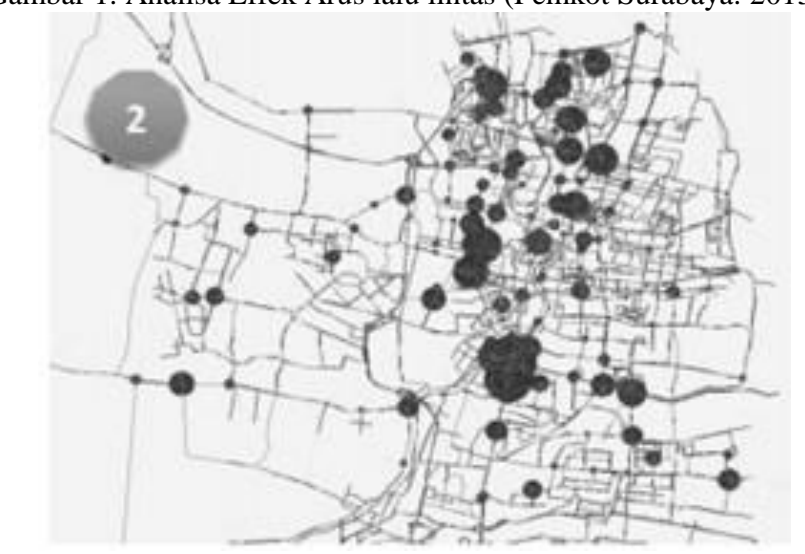

Gambar 2. Rencana titik Feeder MRT (Pemkot Surabaya: 2013)

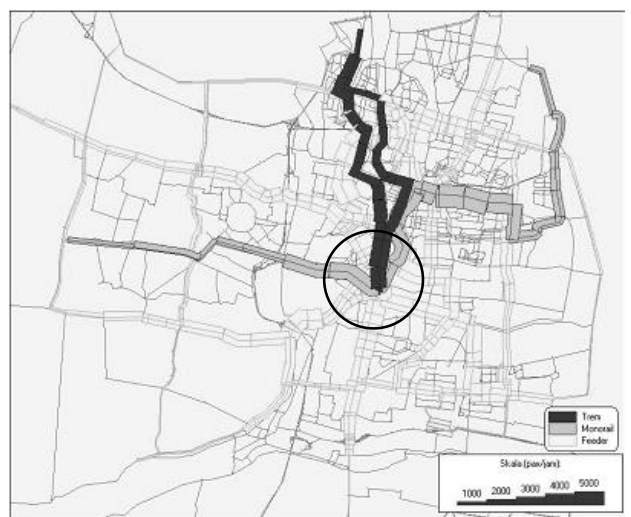

Gambar 3. Perkiraan jalur akomodasi Monorel dan Trem tahun 2030. Joyoboyo sebagai titik perpotongan (www.smart.surabaya.go.id) 
sebagai Terminal kelas B seperti pada Gambar 4 yang memenuhi kebutuhan seluruh kota Surabaya. Terminal Joyoboyo akan menjadi terminal transit atau hub yang mengakomodir moda transportasi seperti, Angkot (Feeder), bus kota (Trunk), Monorel dan Trem. Area ini akan menjadi pusat perpindahan transportasi di kota Surabaya [3].

Berikut data Lahan Terminal Joyoboyo:
Luas
KLB

Tinggi Bangunan : 2-3 Lantai

GSB :6-8 m

\section{METODE DESAIN}

Metode desain merujuk pada metoda arsitek B.I.G atau Bjarke Ingels tentang cara menemukan atau mengarahkan desain arsitektur yang dirasa berhubungan dengan pendekatan yang dipilih yaitu sustainabilitas [4]. B.I.G mengungkapkan beberapa prinsip yang menjadi dasar dari metode dia mendesain arsitektur, yaitu:

Hedonistic Sustaibility: B.I.G berpikir tentang bagaimana sebuah bangunan itu harus sustainable. Dia membungkusnya dengan hal yang menarik agar sustainibilitas ini menjadi sebuah kebiasaan.

Pragmatic Utopian Architecture: B.I.G memberikan pemikiran soal bagaimana arsitektur itu tidak hanya sebagai sebuah konsep pemikiran semata (utopian) namun harus diimplementasikan dengan perhitungan yang logis. Dan B.I.G melakukan ini dengan mengambill beberapa hal yang menjadi inspirasi dia dalam mengembangkan bentuk akhirnya.

Berikut urutan diagram bagaimana runtutan B.I.G dalam menghasilkan sebuah rancangan arsitektur:

Pertama, Memilih sebuah bentukan yang mampu menjadi ikon, atau mengambil bentukan ikonik yang memiliki fungsi serupa atau sejenis, setelah itu dikembangan lagi secara berbeda untuk menghasilkan bentukan yang relatif baru. Hal ini disebut Insapiration Source.

Kedua, Mengembangkan bentukkan bangunan dari morfologi tempat dia beridiri misalnya sekuen, pemandangan (view) dan arus lalu lintas sekitar lokasi objek arsitektur hal ini disebut Augmented Reality Strategy.

Ketiga, Di sinilah peran Pragmatic Utopian Architecture yang menjadi tahap terakhir dalam strategi desain dari B.I.G yang menunjukkan proses untuk mengembangkan desain arsitektur agar mampu memenuhi kebutuhan dari lahan itu sendiri yaitu kebutuhan sosial, ekonomi dan lain lain.

\section{HASIL RANCANGAN}

\section{KONSEP SIRKULASI}

Pada Gambar 5 Konsep sirkulasi mengambil Model central terminating, yaitu mengembangkan satu terminal terpadu yang di sini tidak sebesar kota dalam peninjauannya, namun dalam sekala satu massa bangunan yang ditempatkan

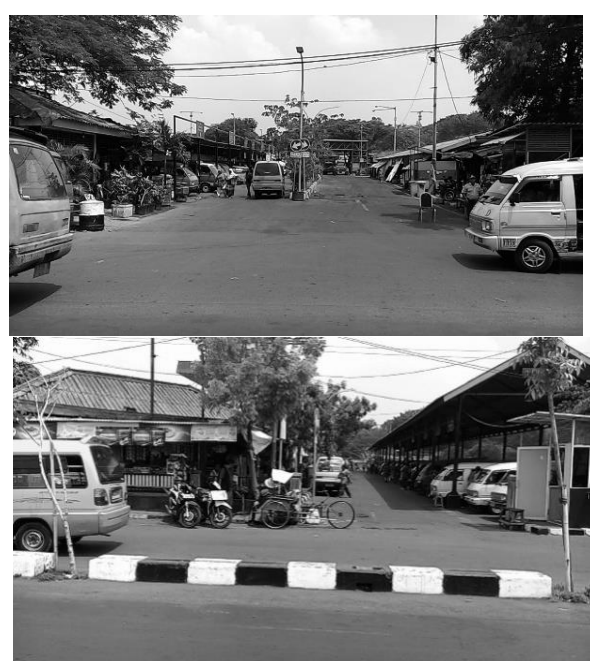

Gambar 4.suasana area Terminal Joyoboyo sekarang
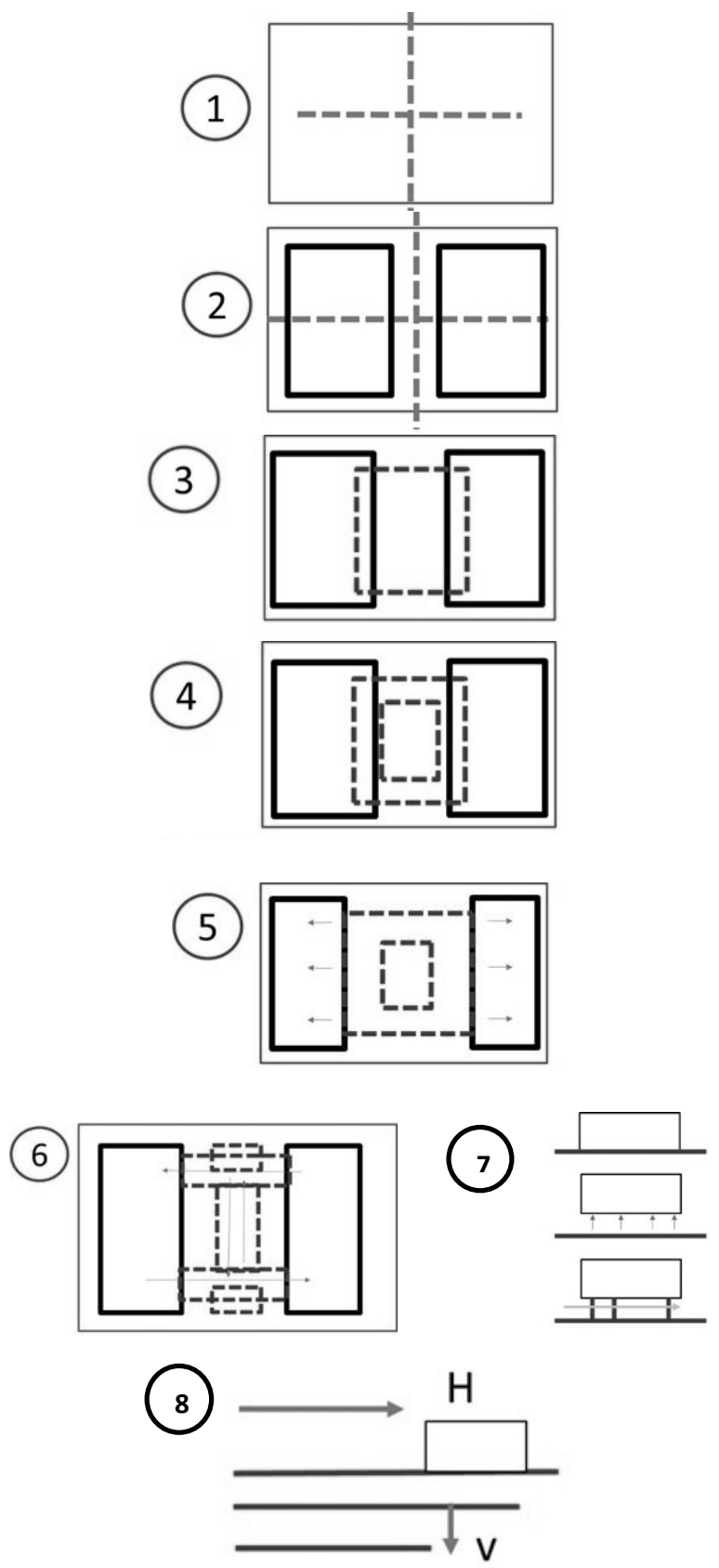

Gambar 5. Diagram Konsep Sikrulasi tahap 1-8 
satu area dimana itu menjadi pusat lalu lalang sirkulasi utama untuk mencapai bebrapa fungsi transportasi atau non transportasi.

Konsep konektor diambil sebagai konsep besar dalam penartaan dan peletakan massa dan arah jalur sirkulasi pada proyek terminal.

Penetapan bentuk diambil dari beberapa parameter seperti:

1. Kelancaran atau orientasi lalu lintas (wayfinding)

2. Efisiensi dan efektifitas jarak

Seperti pada Gambar 5 di atas tentang alur konsep Sirkulasi yang terbagi menjadi 8 langkah dengan prioritas utama uttuk memberikan ruang khusus yang nantinya akan menjadi area gerbang untuk para penumpang mengetahui di mana awal perjalanan mereka untuk menemukan jalan menju moda transportasi lain.

8 langkah dapat dijelaskan sebagai berikut:

1. Pertemuan sekuen sirkulasi secara tegak lurus menghasilkan perpotongan atau pertumpukan sirkulasi.

2. Akibat perpotongan itu terbentuklah titik temu yang nantinya menjadi area penanda.

3. Area dipisahkan menurut prioritas orientasi penumpang dan diperlukan area penghubung.

4. Penghubung berupa sirkulasi bertumpuk berupa kumpulan ekskalator yang menjadi media utama sirkulasi vertikal.

5. Pemaksimalan area penghubung dengan cara memperlebar dan juga sebagai pertimbangan susstainbilitas kapasitas.

6. Area tengah/penghubung ini menjadi kunci keberhasilan terminal dan mengatur sirkulasi di dalam area terminal.

7. Pengangkatan massa untuk memudahkan orientasi penumpang dan penerapan dinding kaca untuk menggantikan dinding beton agar tidak menghalangi jalur pandang penumpang.

8. Mengangkat area/massa yang tertutup untuk menghasilkan akses sirkulasi yang lebih leluasa di bawah untuk moda transportasi trunk, feeder dan drop off mobil pribadi atau taxi.

\section{KONSEP BENTUK , EKSTERIOR DAN INTERIOR}

Untuk mendukung unsur Sustainibiltas dari bangunan ini yang akan menciptkan kesan ikonik dalam area tersebut, perancang menggunakan beberapa unsur di sekitar lahan (morfologi lahan) seperti:

FLUID : Pada Gambar 6.unsur fluid diambil dari Kalimas yang berdampingan langsung dengan lahan dan menjadi salah satu sisi dominan yang terlihat beriringan dengan bentukan bangun

VERTICAL LINE: Pada Gambar 7 unsur garis vertikal serta menunjukkan jalur-jalur transportasi yang diakomodir yang lurus, tegas dan efektif. Ini diterapkan di area tampak dan Interior area masuk platform monorel dan Area tengah lihat Gambar 8 dan Gambar 9.

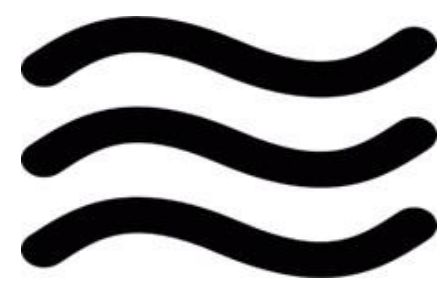

Gambar 6. Konsep bentuk "FLUID"

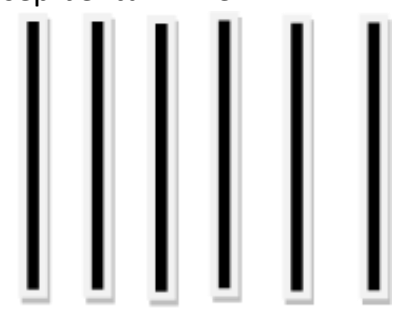

Gambar 7. Konsep Interior \& Tampak "Vertical Line"

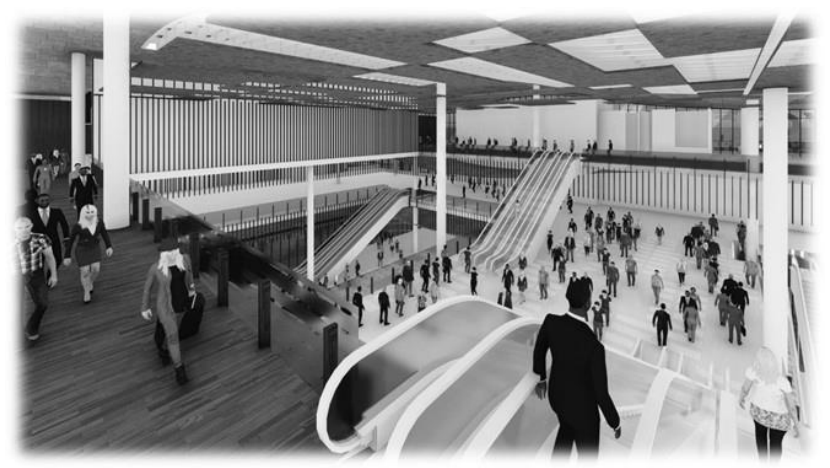

Gambar 8. Suasana Interior Ruang Tengah
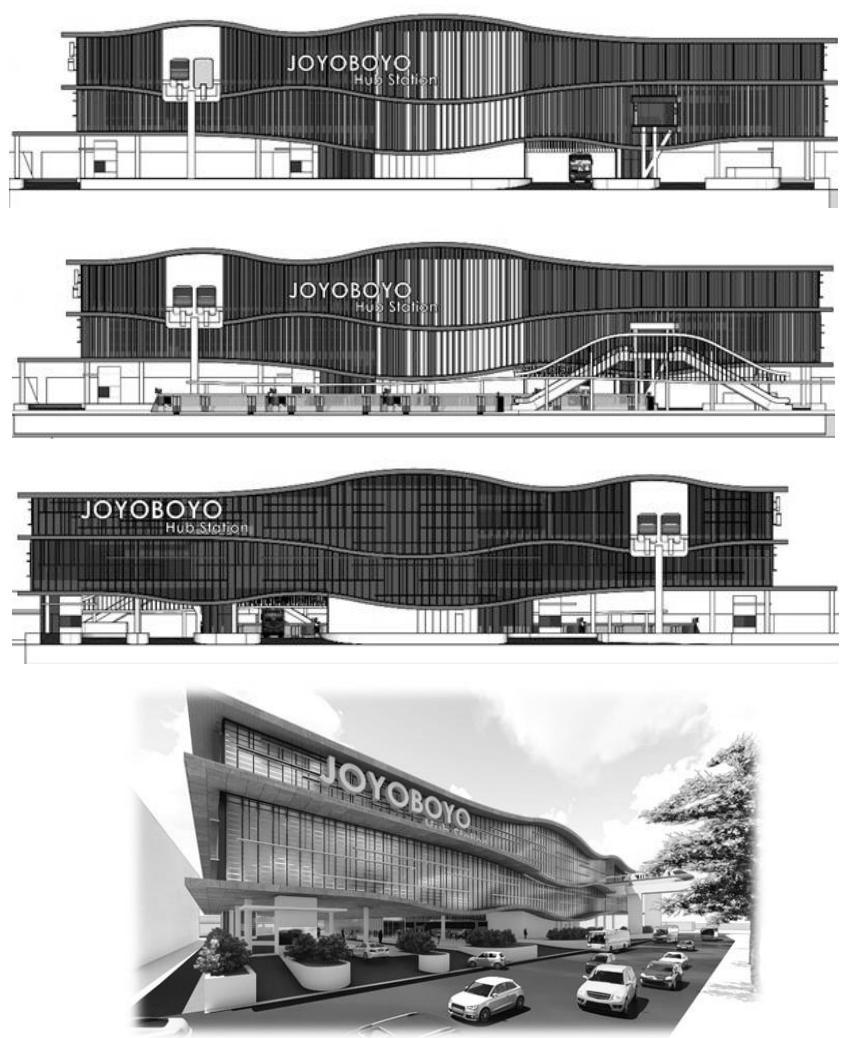

Gambar 9. Implementasi Tampak dan Prespektif 


\section{RINGKASA DAN KESIMPULAN}

Tentang objek rancang area Transit Hub Joyoboyo ini mengutamakan penataan sirkulasi yang tepat dan efektif sebagai konsep rancang utama serta terdapat konsep estetis untuk menguatkan eksistensi dari terminal ini agar masyarakat merasa tertarik untuk menggunakannya dan objek rancang ini juga mampu menjadi ikon area transit di kota Surabaya.

\section{DAFTAR PUSTAKA}

[1] Wahyu, Irvan, (2013), September 30) "Surabaya mass rapid transportation (smart) [online] Available "http://www.slideshare.net/irvanwahyu1/surabaya-mass-rapidtransportation-smart

[2] Muhi, Zuhri. Herijanto, Wahju . (2014). "Manajemen Lalu Lintas Akibat Trem di jalan Raya Darmo Surabaya", [online] Available : http://digilib.its.ac.id/public/ITS-paper-34349-3111106020Paper.pdf

[3] Dinas Perhubungan Kota Surabaya, Badan Pusat Statistik . (2017). “Arus Kendaraan dan Penumpang yang Datang dan Berangkat menurut Jenis Kendaraan Melalui Terminal Joyoboyo 2007-2014". [online] Available

http://surabayakota.bps.go.id/webbeta/frontend/linkTabelStatis/vie w/id/425

[4] Henry, Lyndon. L. Marsh, David . (2008). "Intermodal Surface Public Transport Hubs: Harnessing Synergy for Success in America's Urban and Intercity Travel".[online] available : http://www.vtpi.org/henry_marsh.pdf 